\title{
Estratégias de circulação da pesquisa na universidade
}

\author{
Regina Melim* \\ Universidade do Estado de Santa Catarina
}

\begin{abstract}
Resumo
Como circular as pesquisas realizadas na universidade? Que estratégias podemos criar para que textos, traduções e produções de diferentes ordens possam ser compartilhados em contextos acadêmicos e extra-acadêmicos? Para abordar tais questões, apresento dois projetos: ¿Hay en Portugués? e AULA, ambos integrados como projetos de pesquisa, cujo desdobramentos acontecem nas disciplinas que ministro na Pós-Graduação em Artes Visuais da Universidade do Estado de Santa Catarina.
\end{abstract}

\section{Palavras-chave}

Circular; pesquisa; universidade.

\begin{abstract}
How to circulate the research carried at the university? What strategies can we create that for texts, translations and other productions can be shared in academic and extra academic contexts? To address these issues I present two projects: ¿Hay in Portugués? and AULA, both integrated as a research projects whose developments happen in the courses that I teach in the graduate program of Visual Arts at the University of the State of Santa Catarina.
\end{abstract}

\section{Key-words}

Circulate, research, university. *Professora e pesquisadora da Graduação e da Pós-Graduação em Artes Visuais na Universidade do Estado de Santa Catarina
(Udesc). Também nessa mesma instituição coordena, junto com Raquel Stolf, o Grupo de Pesquisa Proposições Artísticas
Contemporâneas e seus processos experimentais e a Sala de Leitura | Sala de Escuta, espaço que abriga um acervo de
publicações de artista (impressas e sonoras) como lugar de pesquisa, disponibilizado para leitura e escuta a todos os interessados
no tema. Em 2006, criou a plataforma independente parentesis (www.plataformaparentesis.com), e desde então tem produzido e
editado uma série de projetos artísticos e curatoriais no formato de publicações impressas.

Revista do Programa de Pós-graduação em Arte da UnB Vol.15, n²/julho-dezembro de 2016 Brasília
ISSN-1518-5494 ISSN (versão eletrônica):2447-2484 


\section{Tudo começa na sala de aula}

Em 2012, após a realização de um ciclo de seminários apresentados na disciplina "Espaços impressos", que ministrei no Programa de Pós-Graduação em Artes Visuais da Universidade do Estado de Santa Catarina (Udesc), cujo tema era "Publicações de artistas: livros e revistas", contaminados pelas tantas iniciativas impressas pesquisadas e debatidas em sala de aula, surgiu a ideia de realizarmos uma publicação com parte desse material. A intenção era compartilhar e colocar em circulação essa experiência realizada por um grupo de apenas 11 pessoas ${ }^{1}$. Assim, nascia uma publicação, com uma tiragem de 1.000 exemplares impressos, para ser distribuída gratuitamente em lançamentos acompanhados de uma conversa com o público. Como uma espécie de continuidade daqueles mesmos seminários, agora, numa versão aberta e para um público mais amplo.

Batizada de ¿Hay en Portugués?, a publicação nascia impressa em duas lâminas de tamanho $42 \times 60 \mathrm{~cm}$, sem patrocínio algum, totalmente livre e marcada por um modo experimental de expor uma parte daquilo que estávamos produzindo na universidade. Seu formato, não podemos assegurar cem por cento a referência, uma vez que apresentamos e folheamos em sala de aula muitas revistas, como a Navilouca, Malasartes, $A$ Parte do Fogo, Arte em São Paulo, Gávea, item, Concinnitas, Arte \& Ensaios, Recibo, Número, entre outras. Talvez tenha sido A Parte do Fogo a principal referência pela opção de produzir uma revista no formato de dois cartazes, apesar do tamanho ser exatamente o dobro. Mas também não podemos deixar de admitir que somado a isso estavam as restrições econômicas. Restrições que determinaram também a impressão em uma única cor e em papel de baixo custo.

A par de todas essas restrições - 0 que não acarretava nenhum tipo de prejuízo, pelo contrário, elas marcavam uma espécie de adesão com algumas iniciativas que surgem em condições econômicas precárias -, a verdade é que produzir uma publicação dessa natureza implicava, para o grupo em questão, uma conjunção de forças e organização de pensamento de todos aqueles exercícios que nasceram de leituras e apresentações orais. Implicava, também, a criação de estratégias e dispositivos para a sua circulação, uma vez que produção, reprodução e circulação são etapas do processo de uma publicação que devem ser tratadas como inseparáveis e de igual importância. Assim, naquele mesmo ano, em 2012, e no ano seguinte, a publicação ¿Hay en Portugués? número zero - edição experimental circulou em um projeto coordenado por Fabio Morais, Maíra Dietrich e eu, chamado TURNÊ. Tratavase de uma feira itinerante de arte impressa, composta de livros e revistas de

\footnotetext{
${ }^{1}$ Faziam parte: Adriana Barreto, Ana Gil, Bil Lühmman, Daniela Souto, Fabio Morais, Giovana Hillesheim, Janaí de Abreu, Julia Amaral, Lu Renata, Patrícia Peruzzo e Regina Melim. 
artistas, cujo objetivo expresso era o de criar um circuito no qual essa produção artística ganhasse visibilidade2. Nesse circuito, a ¿Hay en Portugués? era distribuída junto a outras tantas iniciativas impressas agenciadas por artistas. Apenas para citar algumas delas: Piseagrama, editada por Fernanda Regaldo, Renata Marquez, Roberto Andrés e Welligton Cançado, em Belo Horizonte; Refil, editada pelo Núcleo de Produção em Artes Gráficas da Escola de Belas Artes da UFMG; A Nuvem, editada pelos alunos da Escola de Belas Artes da UFMG, e Recibo, editada por Traplev, em Recife.

A partir de 2013, com a produção da terceira edição, além de impressa, a ¿Hay en Portugués? passou a contar também com uma versão on-line no site da plataforma parentesis (www.plataformaparentesis.com). E, assim como a edição zero, todas as outras que seguem até o presente momento circulam em feiras de arte impressa, seminários e mesas-redondas em universidades e em exposições, entre outros projetos.

\section{¿Hay en Portugués?}

¿Hay en Portugués? pode ser definida como uma publicação de artista realizada na universidade. Seu título remete a um desejo e uma necessidade de cobrir uma ausência de textos que consideramos significativos para a arte contemporânea que, por razões diversas, nunca foram traduzidos, publicados, reeditados ou veiculados no Brasil. Os textos traduzidos são parte de uma seleção realizada a partir do próprio conteúdo bibliográfico da disciplina. Muitas vezes, os textos são traduzidos na íntegra, em outras, dada a sua extensão, surgem apenas como resenhas.

Poder realizar e colocar em circulação uma publicação com essas características é, sem dúvida, uma conquista de um espaço de sustentação e retroalimentação de nossa produção artística e acadêmica. É inegável, também, que nessa prática sinalizamos a filiação e a adesão que temos com algumas ações impressas, a exemplo das revistas de artistas criadas a partir dos anos 1960. São elas que norteiam não apenas o seu formato: dois cartazes dobrados até formar uma superfície de $20 \times 21 \mathrm{~cm}$, mas todos os traços de independência e informalidade que rondam o seu funcionamento. Nesse sentido, partimos sempre com uma pauta conceitual que agrega uma série de textos que foram selecionados ao longo dos seminários, mas sem a garantia, muito menos a obrigatoriedade, de que todos estarão presentes. Subtrações, adições e desvios são elementos constitutivos do processo de construção de cada uma das edições da ¿Hay en Portugués?.

${ }^{2}$ A TURNÊ percorreu as cidades de Curitiba, São Paulo, Rio de Janeiro e Belo Horizonte. 
Em sua primeira edição, no número zero, se os textos selecionados giravam em torno do tema "Publicações de artistas: livros e revistas", durante 0 processo de produção, uma de nossas primeiras adições foi o texto de Lawrence Weiner "A translation from one language to another", de 1995, cujo primeiro contato foi na versão em espanhol, "Una traducción de un lenguaje a otro", (Alias Editorial, Cidade do México, 2008) que, traduzido para o português e tomado de empréstimo como uma espécie de editorial, expressava conceitualmente parte daquilo que pretendíamos.

se de fato existe a comunicação

toda comunicação é uma forma de tradução

as necessidades \& desejos de um ser humano

requerem uma tradução para a linguagem (arte, música, etc.)

para assim produzir uma estrutura ou situação que

responderá a estas necessidades \& desejos

uma tradução de uma

língua para outra

se de fato todas as coisas devem estar à disposição de todo mundo

cada coisa deve ser adaptável às necessidades de cada grupo de pessoas

(talvez para enriquecer a vida tal como ela é ou talvez para

mudar o que pode ser mudado)

quando uma obra se refere a esses objetos \& materiais

que são em si mesmos uma realidade empírica nem todos os

caprichos possiveis podem transformar viva em vaia

o que se perde é a elegância dentro da cultura

cuja língua foi usada para apresentar a obra

de fato o estilo segue sendo apenas 0

meio de apresentar um conteúdo que deveria

poder funcionar sem nenhum tipo de suporte

uma pedra é uma pedra

isto não evita a sensualidade

do objeto original mas

a tradução permite a cada cultura

adaptar o objeto para satisfazer suas

necessidades particulares

realmente uma tradução é o movimento de

um objeto para outro lugar.

Nova York, dezembro de 1995

\footnotetext{
${ }^{3}$ Entre os textos traduzidos e selecionados para a edição ¿Hay en Portugués? número zero, estão: "Livro de artista como espaço alternativo", de Kate Linker, publicado originalmente na revista Studio International, 1980, n 990, vol. 195, 1980, p. 75-79; "Meus livros terminam no lixo", de Edward Ruscha, publicado originalmente no New York Times, v. 121, n 41, 854, 1972; "Um fim e um começo", de Ulises Carrión, publicado em Umbrella: The Anthology, Umbrella Editions, 1999, p. 22-24; "Questionário para um "Livro de Artista', de Nelson Leirner", publicado no catálogo da exposição Tendências do Livro de Artista, CCSP, 1985, e "Dar é dar", de Eric Watier, publicado na revista Allotopie B, Les Éditions Incertains Sens, 2003, p. 13-25, entre outros. 
A edição número um da ¿Hay en Portugués? surgiu como um desdobramento dos temas abordados nos seminários, mas, também, como um dos desvios há pouco citados. Realizada nesse mesmo ano de 2012, sem estar vinculada a nenhuma disciplina, foi produzida como iniciativa de alguns alunos que haviam participado da experiência anterior, acrescido de outros colaboradores ${ }^{4}$. A motivação maior foi fazer uma homenagem a Lucy Lippard e às suas Numbers Shows, exposições que ela realizou no período de 1969-73, bem como os 40 anos de seu projeto curatorial no formato de livro, Six years: The dematerialization of the art object from 1966 to $1972^{5}$. Um carimbo com a inscrição "I love Lucy"6, impresso em cada exemplar, configurava-se como uma outra forma de adição, como uma marca de filiação e adesão ao seu pensamento e prática nessas últimas cinco décadas, que nas suas palavras eram assim proferidas:

Eu nunca me tornei exatamente uma curadora. A maior parte das cinquenta ou mais exposições das quais eu fiz a curadoria desde 1966 foram pequenas, pouco "profissionais" e frequentemente realizadas em espaços não convencionais, variando entre vitrines de lojas, ruas, sindicatos, manifestações, uma cadeia antiga, bibliotecas, centros comunitários e escolas... Além de alguns museus. Não possuo metodologia curatorial nem qualquer treinamento museológico, exceto por ter trabalhando dois anos na biblioteca do Museu de Arte Moderna de Nova York, quando recém-saída da faculdade. Mas essa experiência - 0 único emprego de verdade que já tive provavelmente me preparou bem para 0 aspecto arquivista e informacional da arte conceitual. [...]

Eu gostava da ideia de fragmentar o meu trabalho também. Nunca considerei a crítica como uma arte em si mesma, separada dos outros assuntos, como alguns consideravam, mas sim como tecer um texto (a raiz etimológica é a mesma), tecido com arte e também com os sistemas que a rodeiam, incluindo exposições. Nos anos 1960, eu estava tentando - às vezes sem muito sucesso - realizar uma aproximação camaleônica (ou parasitária) para escrever sobre arte, escolhendo um estilo de escrita que fosse congruente com o estilo do artista em fazer arte. ${ }^{7}$

Em 2013, realizamos a edição número dois ${ }^{8}$, cujo foco foi a performance, com destaque para as ações latino-americanas. Como ponto de partida, tínhamos uma troca de correspondências entre Alex Hamburger e Ricardo Basbaum com Roselee Goldeberg, conhecida de todos nós pelo seu livro $A$ arte da

\footnotetext{
4 Os principais participantes foram: Adriana Barreto, Bil Lühmann, Fabio Morais, Maíra Dietrich e Regina Melim.

${ }^{5}$ Entre os textos traduzidos e selecionados para a edição ¿Hay en Portugués? número um, estão: "Curadoria por números", de Lucy Lippard, publicado em TATE PAPERS - Tate's Online Research Journal, n’ 12, 2009, e "Conversa entre Seth Siegelaub e Jo Melvin", publicado em From Conceptualismo to Feminism - Lucy Lippard's Numbers Shows 1969-1972, Exhibitions Histories, Afterall, 2012, p. 250-262, entre outros.

6 "I love Lucy" foi também um programa de comédia na televisão estadunidense entre 1951 e 1957.

${ }^{7}$ Disponivel na íntegra em:

http://www.plataformaparentesis.com/site/hay_en_portugues/files/hay_hum_online.pdf

8 Participaram: Adriana Barreto, Bil Lühmann, Cristina Cardoso, Daniela Souto, Leticia Cobra Lima, Maria Simonetti, Marta Facco, Michele Schiocchet, Milene Duenha, Oscar Chica e Vanessa Schultz, e a colaboração de Alex Hamburger, Daniela Mattos, Fabio Morais, Paulo Reis, Regina Melim e Ricardo Basbaum.
} 
performance: do futurismo ao presente. Era uma carta datada de 1989, na qual relatavam que haviam conhecido a primeira edição de seu livro em 1984 e que agora Ihes chegara às mãos uma versão ampliada. $E$ como acreditavam que o trabalho que estavam fazendo estava alinhado com as proposições contemporâneas do campo da performance, acrescido da atração que o livro tinha lhes causado, tomaram a liberdade de fazer esse contato.

Prezada Sra. Goldberg:

Primeiramente, permita que nos apresentemos:

Somos dois artistas do Rio de Janeiro, Brasil; Alex Hamburger \& Ricardo Basbaum, sem perfeito domínio do inglês (pelo que nos desculpamos), respectivamente um poeta e um pintor, ambos desenvolvendo trabalhos em performance art através dos anos 80 , tendo feito uma série de trabalhos durante estes anos que reputamos como inventivos e controversos, dado 0 relativamente pequeno interesse dedicado a práticas artísticas de invenção nesta parte do continente.

Apesar de aqui no Brasil continuarmos consideravelmente dissociados do contexto internacional da arte, acreditamos (temos certeza) que nosso trabalho está alinhado com as proposições mais contemporâneas no campo da performance.

Em 1984, tivemos a chance de entrar em contato com a primeira edição/versão de seu estudo sobre Live Art, considerando-o aliado ao tipo de pensamentofluxo-mental-formas-de-arte com o qual nos identificamos, além de desejar discuti-lo e amplificá-lo. Anos passaram, muitas coisas aconteceram, e a versão ampliada chegou às nossas mãos, sendo esta correspondência 0 resultado da atração contínua que sua pesquisa nos tem causado.

Essas são as principais razões para tomarmos a liberdade de escrever esta carta, desejando expor algumas de nossas concepções e trabalhos em um circuito aberto de transmissão. Pois supomos que a senhora, enquanto pesquisadora de arte, possa estar inclinada a conhecer segmentos tidos como de arte performance produzidos ao redor do mundo (que é a maior de todas as peças de performance), onde o Brasil desempenha um papel razoável, apesar de ainda bastante desconhecido em todo o contexto. [...]

$\mathrm{Na}$ expectativa de sua resposta em um futuro próximo, gostaríamos também de registrar que seríamos capazes de lhe prover maiores informações acerca da performance no Brasil, assim como estabelecer quaisquer trocas culturais que possam lhe interessar.

Por favor, aceite nossas melhores considerações e lembranças.

Atenciosamente,

Alex Hamburger \& Ricardo Basbaum ${ }^{9}$

\section{E Roselee Goldberg respondeu:}

Prezados Srs. Hamburger e Basbaum

Li com interesse seus contos acerca de noites sul-americanas, homenagem a John Cage, revistas e vida noturna, e estarei sempre satisfeita em receber informações sobre suas atividades.

Obrigada por sua carta,

\footnotetext{
${ }^{9}$ Disponível na íntegra em 
Atenciosamente

Roselee Goldberg

A partir daí, tomamos a decisão de realizar um breve desvio e publicar na edição número dois da ¿Hay en Portugués? uma lista de performances latinoamericanas, no formato de um texto corrido, numa ordem que não era cronológica, mas de associações de memória, cobrindo exemplos datados desde a década de 1930 ao presente, ocorridos no Brasil, Argentina, Uruguai, Chile, Peru, Colômbia, Venezuela e México ${ }^{10}$.

Em 2014, realizamos a edição número três ${ }^{11}$ com o tema "Outros espaços da arte", incluindo desde espaços físicos experimentais, criados e ocupados por artistas, até a criação de revistas e demais impressos. Nosso ponto de partida foi uma entrevista realizada por Skype entre a artista nova-iorquina Martha Wilson, fundadora da Franklin Furnace, em 1976, em Nova York, e Michele Schiocchet, aluna da pós-graduação que naquele semestre estava realizando parte de seu doutorado na New York University. A conversa com Martha Wilson conjugava os dois temas que havíamos abordados em edições anteriores da ¿Hay en Portugués?, livros de artista e performance. Uma feliz coincidência, sem dúvida, mas o certo é que já estávamos na "trilha" de Martha Wilson havia bastante tempo. Além disso, nosso interesse voltava-se também para a história e a manutenção de dois espaços criados e agenciados por artistas e que permanecem em pleno funcionamento até o presente, a Franklin Furnace e a Printed Matter, ambos iniciativas que surgiram juntas, no mesmo ano de 1976. Num trecho da conversa com Martha Wilson, ela discorre sobre esse momento:

Comecei, então, uma organização sem fins lucrativos e ia chamá-la de The Franklin Stove, mas Willoughby disse "não, você tem que chamar de Franklin Furnace!". Ele achou que esse era o nome certo. Ao mesmo tempo em que eu estava correndo atrás de incorporar minha organização, a Printed Matter estava sendo fundada por um coletivo de mais ou menos doze pessoas: Sol LeWitt, Pat Steir, Robin White, Walter Robinson, Edit DeAk... Não consigo lembrar de todas as pessoas, Carl Andre, Mimi Wheeler, enfim, havia muitos, então eles não conseguiam se mover tão rapidamente quanto eu conseguia, pois eu estava tomando decisões sozinha, e eles tomavam decisões entre os doze. Eles, então, se formaram um pouco depois como uma organização com fins lucrativos. A razão para quererem ser "com fins lucrativos" era porque não queriam o governo estadunidense dizendo a eles: "esse trabalho é político demais, não queremos que vocês publiquem isso". Eles queriam liberdade para publicar o que quisessem. Eles também sentiram que era necessária a distribuição, pois os artistas estavam produzindo livros de artista que não

${ }^{10}$ Ainda, dentre os textos traduzidos e selecionados para a edição ¿Hay en Portugués? número dois estão: A performatividade da documentação de performance, de Philip Auslander, publicado em Performance Art Journal - PAJ, n. 84, 2006, pp. 1-10 e Sobre Performance (e outras complicações), de Jens Hoffmann e Joan Jonas, publicado em Perform, Thames \& Hudson, 2005, pp. 1117 , entre outros.

${ }_{11}$ Participaram: Adriane Kirst, Alice Sinzato, Bruna Maresch, Carolina Votto, Fabíola Scaranto, Fernando Boppré, Fernando Weber, Leandro Serpa, Mônica Age, Oscar Chica, Pablo Paniagua, Pedro Franz, Regina Melim, Virginia Yunes e a colaboração de Ana Paula Felicíssimo Lima, Michele Schiocchet e Martha Wilson. 
ficavam disponíveis. A não ser que fosse você que tivesse feito o livro, não se conseguia o livro. Eles, então, queriam fazer publicação e distribuição. Eu havia aberto as minhas portas em abril, e eles abriram as portas em julho (ou depois). A essa altura, eu percebi que gerir uma livraria significada ficar de pé na fila dos correios (risos). Isso era o meu negócio. Eu simplesmente preferi desistir da parte relativa à distribuição. Tivemos algumas discussões, e eu então fiquei com as atividades sem fins lucrativos: exposições, arquivos... E eles tomaram as atividades com fins lucrativos: publicação e distribuição. Houve alguns momentos de tensão, quando pensei que a Printed Matter e a Franklin Furnace deveriam ocupar a mesma fachada na Franklin Street. Novamente, Willoughby Sharp disse: "não, senão ficaremos conhecidos como o prédio da Printed Matter", e ele não queria isso. Havia excitação, e o processo era um pouco tortuoso, mas basicamente o que fizemos foi dividir a torta dos livros de artista em duas metades, e cada um tomou essa metade para realizarmos juntos o todo. ${ }^{12}$

Na sequência, textos abordando as cinco décadas do Fluxus e uma seleção de revistas de artistas estadunidenses criadas nos anos 1960-70 não apenas totalizavam esta edição, mas configuravam-se como aproximações e diálogos com a conversa com Martha Wilson ${ }^{13}$.

Em 2015, a edição número quatro ${ }^{14}$ prosseguiu com o mesmo tema, "Outros espaços da arte". Nosso ponto de partida foi o livro Undermining: a wild ride through land use, politics, and art in the changing West, de Lucy Lippard. Ainda que 0 assunto estivesse circunscrito ao solo estadunidense, ficava explícito (e por isso o nosso maior interesse) que as questões que Lippard apontava eram globais. Nas suas palavras:

O título Undermining surgiu desde o início desse projeto: literalmente minar - como os buracos e veios que refletem a cultura, alteram ecossistemas irreversivelmente e geram novas estruturas; as consequências físicas de minar, suas cicatrizes no corpo humano político; minar da forma como estamos minando o nosso continente e 0 nosso planeta quando triunfam, juntas, a ganância e a desigualdade; minar como um ato político - a subversão como uma das formas de resistência dos artistas. 15

12Disponível na íntegra em:

http://www.plataformaparentesis.com/site/hay_en_portugues/files/hay_tres_online.pdf

${ }^{13}$ Entre os textos traduzidos e selecionados para a edição ¿Hay en Portugués? número três, estão: "Revistas de arte e arte de revistas", de Clive Philpot, publicado originalmente na Revista Artforum, v. 18, n 6, fev. 1980, p. 52-54, e textos sobre as revistas Artforum (1960-70), Art Rite e Real Life produzidos a partir de leituras e traduções de Artist's magazines: an alternative space for art, de Gwen Allen, Cambridge, MIT Press, p. 13-41, p. 121-145 e p. 175-199.

14Participaram: Alvaro Diaz, Annaline Curado, Caroline Schroeder, Daniele Zacarão, Denise Helfenstein, Jaymini Shah, Jorge Bucksdricker, Juliano Ventura, Kim Coimbra, Luana Navarro, Lucelia Veiga, Luciana Mendonça, Marcia Figueiredo, Paulo Damé, Rafael Zen, Regina Melim, Sílvia Carvalho e Tatiana Rosa.

${ }^{15}$ Disponivel na íntegra em:

http://www.plataformaparentesis.com/site/hay_en_portugues/files/hay_quatro_online.pdf

Revista do Programa de Pós-graduação em Arte da VIS Vol.15, n²/julho-dezembro de 2016 Brasília
ISSN-1518-5494 ISSN (versão eletrônica):2447-2484 
Quatro anos se passaram, e o projeto ¿Hay en Portugués? conta com cinco edições publicadas (fig.1). Assinalei, no início deste texto, que partimos sempre com uma pauta conceitual que agrega alguns textos que foram selecionados ao longo dos seminários que realizamos nas disciplinas. A cada ano, outros temas e textos são apresentados, debatidos, selecionados, traduzidos (nem sempre nessa ordem) e publicados. E, se a intenção inicial era compartilhar e colocar em circulação uma experiência realizada por um grupo de pessoas dentro de uma sala de aula, imprimindo e distribuindo a publicação em diferentes situações e contextos, hoje podemos dizer que a publicação ¿Hay en Portugués? tem se configurado, também, como um importante material de consulta bibliográfica.

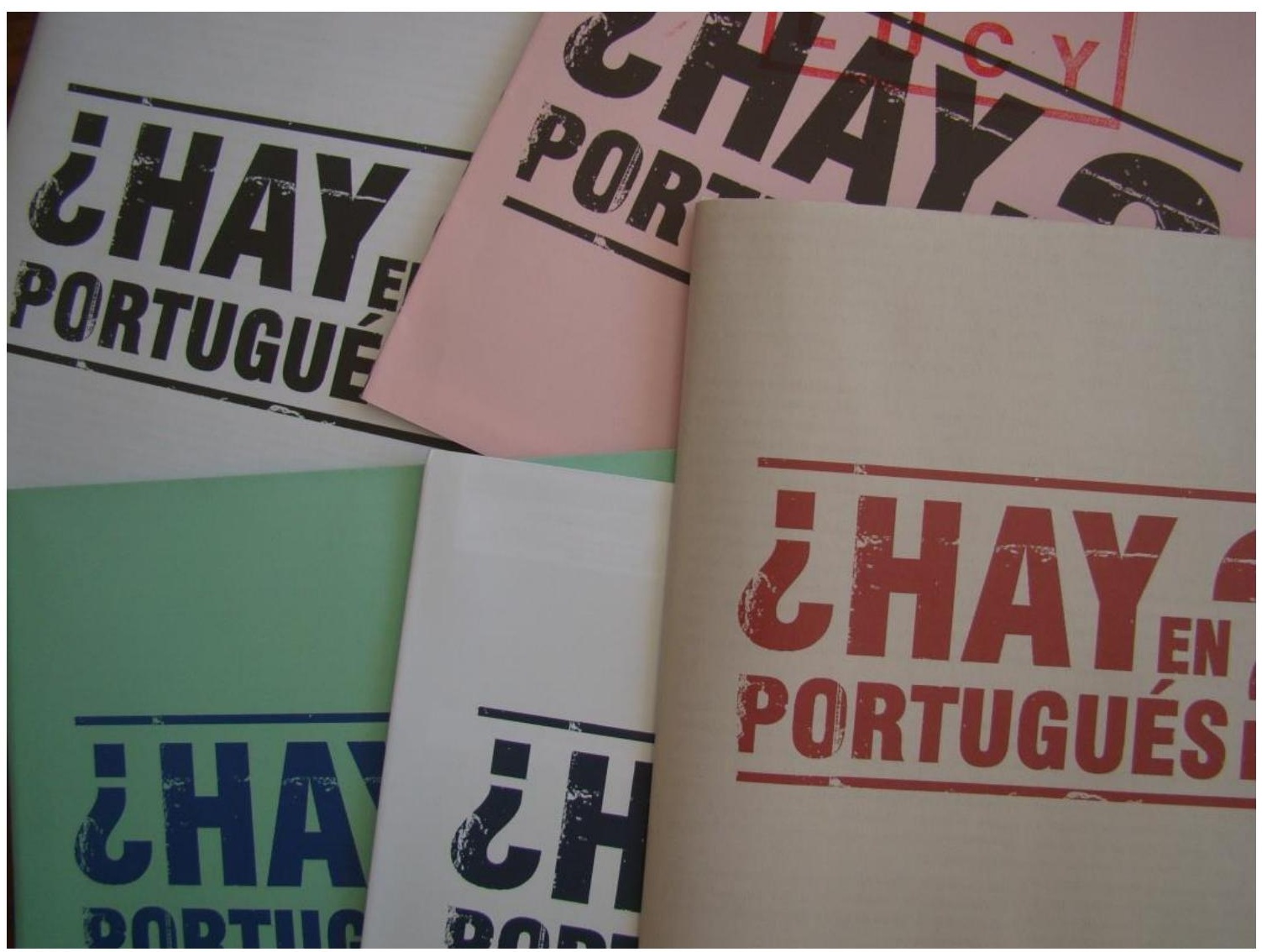

Fig. 1. Diferentes edições de ¿Hay en Portugués?; fonte: autora.

\section{AULA}

Em 2015, um outro projeto nasceu com a mesma intenção: circular práticas desenvolvidas em sala de aula. Mas surgiu também como resultado de uma série de inquietações e reflexões que nascem de uma prática ao longo de 20 anos como professora na universidade. Denominado de AULA, o projeto consiste em convidar anualmente um artista para ministrar uma aula, e parte do conteúdo apresentado pode ser compartilhado com uma publicação 
impressa, cuja tiragem é de 500 exemplares. Uma vez impressa a publicação, AULA segue a mesma trajetória da ¿Hay en Portugués?, ou seja, a circulação em feiras de arte impressa, seminários e mesas-redondas em universidades e em exposições, entre outros projetos.

0 projeto teve início com o artista Fabio Morais ministrando aula para alunos das disciplinas "Curadoria" (Graduação em Artes Visuais) e "Outros espaços da arte" (Pós-Graduação em Artes Visuais). Parte de sua apresentação em sala de aula, cujo tema principal era a sua coleção de livros, por ele denominada de "Bacanas Books", gerou a publicação AULA 01: Rodapé, desenvolvida a partir de três questões: 1) A coleção de publicações de artista como lugar de pesquisa; 2) A publicação de artista como procedimento artístico; e 3) O desafio curatorial de expor quando a publicação de artista, ela mesma, já se configura como uma exposição. Algumas dessas questões foram assim descritas pelo artista:

Sou artista visual e tenho uma biblioteca de publicações de artista que se chama Bacanas Books.

O primeiro livro que adquiri para a coleção, quando ainda nem existia a pretensão de uma coleção, foi Velazquez, de Waltércio Caldas, no final da década de 1990. Antes de dizer que a partir daí a Bacanas Books foi se tornando meu ateliê, lugar de trabalho e pesquisa, devo admitir que ela é meu campo de autorreconhecimento.

Preciso de eletrodomésticos que me ajudem na mecânica cotidiana da casa. Preciso de janelas que me mostrem o mundo enquanto dele me aparto. Preciso de canetas e papéis espalhados ao alcance das mãos, mesmo intocados. Preciso de água. Luz elétrica. Preciso também de livros que me mostrem meu campo simbólico. Entendo talvez o melhor verbo seja "enxergo" - essa necessidade quando vejo na rua mendigos rodeados de tralhas que vão juntando e formando seu território. Os livros são as tralhas que me dão a sensação pessoal de território. [...]

Como um dicionário que arquiva as palavras do idioma, com a Bacanas Books eu arquivo o vocabulário artístico com o qual articulo meu próprio trabalho. Apropriação, metarreferência, arte conceitual, escrita, arquivo, fabulação histórica e ficção são questões recorrentes nos livros que compro e, de forma naturalmente espelhada, são também recorrentes nos trabalhos que faço. Assim, a Bacanas Books amplia meu vocabulário livro a livro e forma um discurso cuja sintaxe é a própria coleção. Ao pesquisar que sintaxe natural e orgânica é essa que meu ato colecionista forja pela casa, acesso de forma natural as "leis" da minha prática artística. Nesse sentido, além de território, a Bacanas Books é lugar de pesquisa e trabalho e configura-se como 0 ateliê que jamais tive. ${ }^{16}$

Se, inicialmente, a ideia era trazer um artista para ministrar uma aula, cujo tema era algo que previamente já havíamos planejado como conteúdo da disciplina, após a realização de sua primeira edição, em abril de 2015, e sua posterior publicação, em outubro desse mesmo ano, novos contornos e aprofundamentos foram feitos nesse projeto. $O$ fato de nosso primeiro convidado ter sido um aluno que havia participado de nossas aulas e

${ }^{16}$ Aula 01: Rodapé foi publicado pela plataforma parentesis (www.plataformaparentesis.com) em outubro de 2015. 
seminários na pós-graduação, e agora retornava como ex-aluno, nos sugeriu a possibilidade de prosseguir 0 projeto AULA sob uma outra perspectiva, endereçando nossa decisão, dali em diante, para que o convidado para ministrar uma aula pudesse ser sempre um ex-aluno.

E, da mesma maneira que a ¿Hay en Portugués?, as publicações do projeto AULA visam ao mesmo objetivo, que é o de sustentação e retroalimentação de produção de pesquisa e que, uma vez postas em circulação, ampliam e promovem outros compartilhamentos muito além de uma sala de aula (figs. 2 e 3).
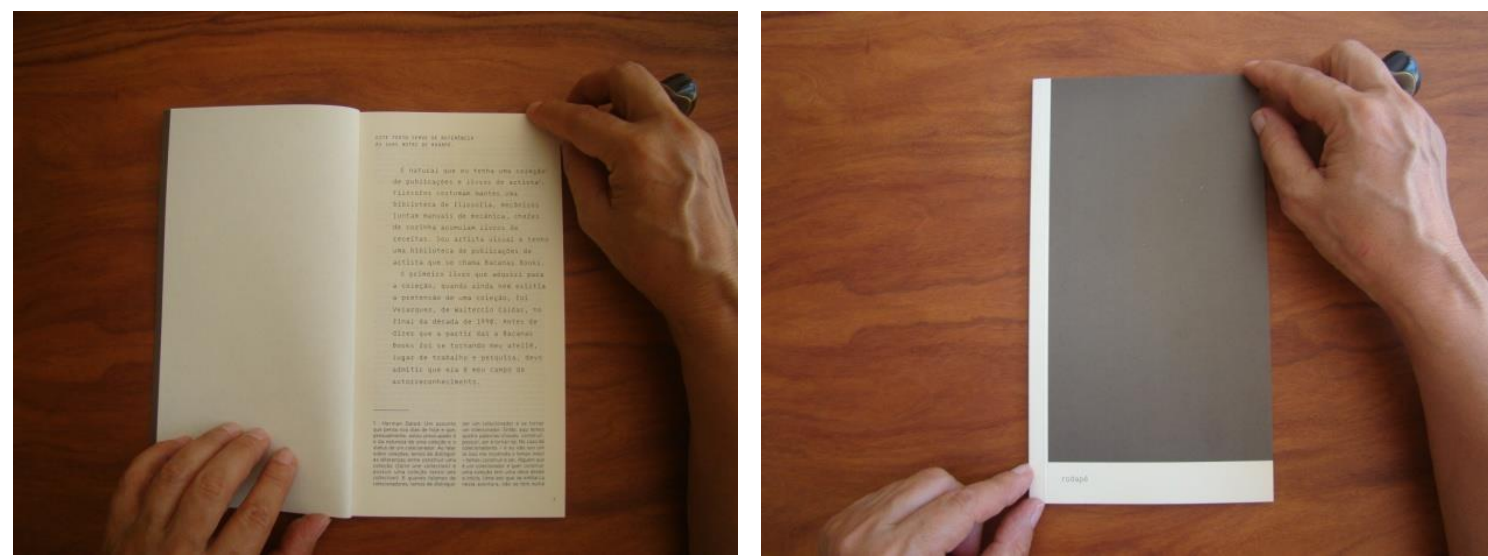

Figs. 2 e 3. AULA; fonte: autora.

\section{Publicar (e distribuir)}

Nos dois exemplos citados, ¿Hay en Portugués? e AULA, temos que admitir que a primeira estratégia para a circulação de nossa produção acadêmica e artística partiu com a iniciativa de publicar os seminários realizados em sala de aula. Publicá-los, ainda que fossem no formato de resenhas e excertos de traduções, ou seja, apenas uma parcela daquilo que tínhamos apresentado e debatido no decorrer de um semestre, equivalia a ampliar o nosso espectro de atuação como artistas pesquisadores. Aderida a essa iniciativa, surgia também a estratégia de distribuir, de fazer chegar esse conteúdo a outros contextos, como forma de continuidade e desdobramento de nossa atividade de pesquisa na universidade. Assim, surgiam juntas, publicação e distribuição, a partir de um cronograma de atividades possíveis que incluía participações em seminários, conversas e mesas-redondas, feiras e exposições, e textos. Todos, como estratégia contínua para dar conhecimento de uma prática de pesquisa e de ensino desenvolvida no âmbito acadêmico, dentro de uma sala de aula. 